\title{
Kant, Hegel, and the Transcendental Material Conditions of Possible Experience Kenneth R Westphal
}

\section{Introduction}

For both methodological and substantive reasons Hegel owes us a thorough internal critique of Kant's transcendental idealism. ${ }^{1}$ He did not, however, set one out. I have become convinced, however, that Hegel's reading and re-thinking of Kant during his years in Jena is far more thorough and insightful than has generally been recognized, and that he was clearly aware of some very important main lines of internal criticism to which Kant's philosophy is subject.

Here I want to develop one case of an obliquely indicated but nevertheless sound objection Hegel makes to Kant's transcendental idealism. The issue concerns what Kant calls the "transcendental affinity of the manifold of intuition." This phrase denotes the necessary degree of regularity among the content of empirical intuitions such that we are both able and stimulated to comprehend that content under our general concepts and categories in empirical judgments. Kant is quite clear that this is a transcendental condition for the possibility of experience. It is also a formal condition, since it concerns the ordering of something, in this case, of the contents of empirical intuitions. Kant contends that transcendental idealism, and it alone, can account for the transcendental affinity of the manifold of intuition. Against Kant, I shall contend that transcendental idealism cannot account at all for the occurrence of the transcendental affinity of the manifold of intuition. Before turning to some of the details of Kant's views, I shall show that this problem is very much on Hegel's mind in Jena. Afterward I shall show that understanding Hegel's concern about Kant's views on the transcendental affinity of the manifold of intuition sheds light on some of Hegel's otherwise rather puzzling claims and aims.

\section{Two Examples of Hegel's Brief Critical Insights}

Since the issues and arguments I will ascribe to Hegel may seem to make way too much philosophical substance out of far too little textual evidence, I should like to begin by noting two parallel cases. These are cases of brief remarks Hegel makes about Kant in his early writings, almost in passing, which in fact indicate very fundamental problems with Kant's philosophy.

In connection with Kant's 'Mathematical' Antinomies in Faith and Knowledge ("Glauben und Wissen", 1802) Hegel briefly criticizes Kant's account of our 'infinite progress" in virtue, set out in the Critique of Practical Reason. Hegel states:

Of course if this negative [solution to the mathematical antinomies provided by transcendental idealism] were already sufficient, [it would] at least avoid the infinite progress for practical reason, since this is just the same antinomy as the 
infinite regress, and indeed only for and in finitude. Practical reason, which takes recourse to this progress, and which should constitute itself in freedom as absolute, comes to know through this infinite progress its [own] finitude and incapacity to make itself absolutely valid. ${ }^{2}$

At the end of the essay Hegel returns to the topic of Kant's moral philosophy and adds another charge:

The true identity must stand as an absolute beyond over and against such a formal knowledge, which cannot get beyond a relative identity nor beyond its absolute opposite, which in Kant has the popular and less abstract form of happiness and morality. This is because thought and knowledge are simply formal, simply in opposition, and simply relative. Thus rational knowledge and speculative idea are immediately sublated and impossible. The highest striving of formal thought is the recognition of its own nothingness and of the ought; but because it does not truly give itself up, the ought is perennial ... ${ }^{3}$

Now Hegel is entirely confident about these criticisms here, although he doesn't spell them out in any detail. His main points are that Kant's account of our infinite post mortem progress in virtue is incoherent, that Kant fails to integrate happiness and morality, and that these failures ultimately undermine the validity of Kant's account of practical reason. These charges form the kernel of Hegel's criticism of Kant in "The Moral View of the World" in the Phenomenology of Spirit. There Hegel works out these charges in great detail, although he doesn't footnote Kant's texts. I have shown elsewhere that in fact Hegel's criticisms are very closely tied to Kant's views and texts, and that at least five of his objections are sound. ${ }^{4}$

A second case of a brief but ultimately decisive objection is found in Hegel's apparently passing remark about Kant's Metaphysical Foundations of Natural Science in the Differenzschrift (1801):

For [Kant], ... forces are not merely superfluous; they are either purely ideal, in which case they are not forces, or else they are transcendent. The only construction of phenomena that he can allow is mathematical, not dynamical. ${ }^{5}$

In fact, Hegel is quite right about this. As I have shown in detail elsewhere, Kant's "metaphysical constructions" of the concept of matter do not at all prove Newton's law of inertia, which is of course crucial to Newtonian physics. Moreover, Kant's constructions fail to show that all physical causality is external. This premise is crucial not only to physics, but also to common sense judgments about every day objects. In fact, without this premise, Kant cannot justify any of the principles of causal judgment defended in the Analogies of 
Experience. Hegel's objection thus undermines Kant's most important positive arguments in the Transcendental Analytic. ${ }^{6}$

\section{Some interpretive difficulties}

There are, however, some interpretive problems involved in ascribing to Hegel awareness of precisely the problem involved in the transcendental affinity of the manifold of intuition. In the two cases just mentioned there is quite clear and definite reference to Kant's texts and doctrines which provide unequivocal grounds for ascribing to Hegel rather elaborate and specific objections on the basis of rather brief remarks. Regarding the transcendental affinity of the manifold of intuition, on the other hand, Hegel's remarks are numerous, though brief, and they do not identify by name the issue of the transcendental affinity of the manifold of intuition. One reason Hegel may not have identified this topic by this name is that he worked with the second edition of Kant's Critique, in which most of the passages containing this phrase were omitted ${ }^{7}$ I have shown elsewhere, however, that this issue is equally central to Kant's views in both editions, and that some important passages discussing it are included in both editions.

Hegel develops the problem involved in the transcendental affinity of the manifold of intuition in a variety of ways, often in connection with Kant's successors. However, for several reasons I believe the ascription of a distinct awareness of the problem to Hegel is legitimate. First, the problems addressed by immediately post-Kantian philosophers were current because they arose already as problems in Kant. ${ }^{9}$ Second, Hegel does develop the problem in connection with Kant. Third, Hegel actually devotes more frequent and detailed attention to this problem in his early writings than he did to either of the problems mentioned above and each of them are sound and telling. I shall show that this problem, regarding the transcendental affinity of the manifold of intuition, is equally sound and telling. It provides the lynch pin which both holds Hegel's various formulations together, and ties them to a central problem in Kant's transcendental idealism.

Having said that, I should perhaps issue a caveat. I shall appeal freely to brief excerpts from the early writings. Although Hegel's early writings formulate or at least indicate many of the central problems Hegel addressed in his mature philosophy, they do so within an immature, still developing, often obscure philosophical framework. This is to say, I will not attempt the absurd project of improving on Henry Harris's comprehensive reconstruction of Hegel's Jena writings in just one essay. ${ }^{10}$ I will unabashedly mine Hegel's early writings for the light they shed on his mature philosophy, beginning with the Phenomenology of Spirit. Considering the problems with Kant's views on transcendental affinity, and considering Hegel's interest in them, provides an independent line of support for the kind of holistic realism coupled with quasi-transcendental regressive arguments which I have shown to characterize Hegel's position in the Phenomenology. ${ }^{11}$ 


\section{Traces of the Problem of Transcendental Affinity in Hegel's Early Writings}

In general, Hegel was disturbed by Kant's account of nature. He asserted that philosophy must recompense nature 'for the mishandling that it suffered in Kant and Fichte's systems, and set reason itself in harmony with nature." 12 One way Hegel characterizes the problem which turns out to be the problem of the transcendental affinity of the manifold of intuition is this: The basic problem in Kant's metaphysics is that it does not explain the "most interesting aspect of the objective world, the aspect of its reality" and that the most fundamental question "is not at all about ideality, but about reality, and it does not matter whether the reality concerned is an infinite mass of sensations or of thing-qualities." $13 \mathrm{He}$ is well aware that if our mind is to contribute the structure of our experience, then the matter of experience must be unstructured, indeed so unstructured that it seems "the world is always falling to pieces." 14 Hegel is, in a word, very interested in the order, or lack thereof, in the manifold of empirical intuition, and in Kant's account of that order - an issue he also pursues in connection with Fichte. ${ }^{15}$

Analogously, Kant's account of the relation between conceptual form and the matter of sensation is central to Hegel's description of Kant's philosophy as a dualism:

A formal idealism which in this way sets an absolute ego-point and its intellect on one side, and an absolute manifold, or sensation, on the other side, is a dualism. $^{16}$

Indeed, Hegel paraphrases Kant's direct statement of this dualism from the third Critique $(\S 76)$ :

The intellect is for concepts, sensuous intuition for objects - they are two entirely heterogenous parts. ${ }^{17}$

Other passages also demonstrate Hegel's awareness of the contingency of nature and the matter of sensation with respect to our categories. ${ }^{18}$

Third, Hegel repeatedly stresses the importance of the material conditions which must be fulfilled in order for judgment to be possible, namely, the matter of sensation must be such as to be subsumable under our concepts. In the Differenzschrift he presses this point against Kant's immediate successors Reinhold and Bardili, ${ }^{19}$ and in Faith and Knowledge he presses it several times against Kant himself. ${ }^{20}$

Finally, in precisely this same vein Hegel sought principles governing the a posteriori realm of the given matter of experience:

Outside what is objectively determined by the categories there remained an enormous empirical realm of sensibility and perception, an absolute $a$ posteriori 
realm. For this realm the only a priori principle discovered is a merely subjective maxim of the faculty of reflecting judgment. ${ }^{21}$

In sum, Hegel is quite well aware that there must be some order in the matter of sensation if we are to have experience at all, and that there must be some rational principle which governs that order, although it cannot be one of Kant's Principles of the Understanding (ie, the Analogies) or of Reflective Judgment. The irony is that Kant did propound such a principle, namely the principle of the transcendental affinity of the manifold of intuition, and indeed he established it soundly within his transcendental arguments for the conditions of possible experience, though ultimately Kant cannot account for it within the framework of his transcendental idealism. Hegel is definitely aware of a key problem. Let's see why.

\section{Kant's Problem with Transcendental Affinity}

The phrase in my title, "transcendental material conditions of experience", may seem oxymoronic. It is not. A crucial feature of Kant's 'formal" idealism is that the matter of experience is given to us $a b$ extra. This is itself a transcendental material condition of experience. $^{22}$ There may be difficulties understanding just how Kant thinks this material is supplied, but the condition itself is not incoherent. ${ }^{23}$ The oddity really lies in the only other transcendental material condition of experience Kant recognized, namely, the transcendental affinity of the manifold of intuition. This condition is peculiar because it is both transcendental and formal, and yet neither conceptual nor intuitive, but rather material. This is to say, the transcendental affinity of the manifold of intuition is transcendental because it is a necessary $a$ priori condition of the possibility of experience. It is formal because it concerns the orderliness of the matter of empirical intuition. However, ultimately it is satisfied neither by the a priori intuitive conditions of experience analyzed in the Transcendental Aesthetic nor by the a priori conceptual conditions analyzed in the first part of the Transcendental Analytic. As Kant twice acknowledges, its satisfaction is due to the "content" or the "øbject" of

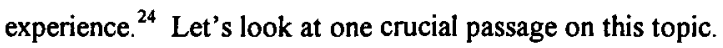

Appearances must be associable in order for us to make cognitive judgments at all. This associability, Kant argues, must have an objective, necessary ground in order for experience to be possible at all. This ground is what Kant calls the "affinity" of the manifold of intuition:

Now if this unity of association did not also have an objective ground, so that it would be impossible for appearances to be apprehended by the imagination otherwise than under the condition of a possible synthetic unity of this apprehension, it would be entirely accidental that appearances should fit into a connection in human knowledge. For even though we should have the capacity to associate perceptions, it would remain entirely undetermined and accidental 
whether they themselves were associable; and in case they were not associable, then a multitude of perceptions, and indeed an entire sensibility would be possible, in which much empirical consciousness would be found in my mind, but separated, and without belonging to one consciousness of myself, which, however, is impossible. For only because I ascribe all perceptions to one consciousness (original apperception) can I say of all perceptions that I am conscious of them. There must, therefore, be an objective ground (that is, one that can be comprehended a priori, antecedent to all empirical laws of the imagination) upon which rests the possibility, indeed, the necessity, of a law that extends to all appearances - a ground, namely, for regarding all appearances as data of the senses that must be associable in themselves and subject to universal rules of a thoroughgoing connection in their reproduction. This objective ground of all association of appearances I entitle their affinity. It is to be found nowhere else than in the principle of the unity of apperception, in respect of all cognitions which should belong to me. According to this principle all appearances, without exception, must so enter the mind or be apprehended, that they conform to the unity of apperception. Without synthetic unity in their connection, which is thus objectively necessary, this would be impossible.

The objective unity of all (empirical) consciousness in one consciousness, that of original apperception, is thus the necessary condition of all possible perception; and the affinity of all appearances, near or remote, is a necessary consequence of a synthesis in imagination which is grounded a priori on rules. $^{25}$

In this passage Kant points out that a complete sensibility and understanding, capable of associating perceptions, does not of itself determine whether any appearances or perceptions it has are in fact associable. If they weren't, there may be fleeting episodes of empirical consciousness (ie, random sensations), but there could be no unified, and hence no selfconscious, experience. In part this would be because those irregular perceptions would not admit of any reproductive synthesis; they wouldn't admit of any psychological association, and so couldn't afford a basis for developing empirical concepts or for applying categorial concepts to objects. (There could be no schematism of categories in a world of chaotic sensory intuitions.) In this regard, the necessity of the associability of the manifold of intuition is a conditional necessity, holding between that manifold and any self-conscious (human) subject. Necessarily, if a human subject is self-consciously aware of an object via a manifold of intuition, then the content of that manifold is associable. The associability of this content is its "affinity." The fact that affinity is necessary for the possibility of experience entails that this affinity is transcendental. 
Kant makes the transcendental status of this issue plainest in a passage contained in both editions of the first Critique, though here he speaks of a "logical law of genera" instead of the "transcendental affinity of the manifold of intuition":

If among the appearances which present themselves to us, there were so great a variety - I do not say in form, for in that respect appearances might resemble one another; but in content, that is, in the diversity of existing entities - that even the acutest human understanding could never by comparison of them detect the slightest similarity (a possibility which is quite conceivable), the logical law of genera would absolutely not obtain, and there would not even be the concept of a genus, or any other universal concept, or indeed any understanding at all, since it has to do solely with such concepts. If, therefore, the logical principle of genera is to be applied to nature (by which I here understand only those objects which are given to us), it presupposes a transcendental principle [of genera]. In accordance with this latter principle, homogeneity is necessarily presupposed in the manifold of possible experience (although we cannot determine a priori its degree); for without homogeneity, no empirical concepts, and hence no experience, would be possible. ${ }^{26}$

Despite the shift in terminology, it is plain that the condition that satisfies the "logical law of genera" is the very same as that which satisfies the "transcendental affinity of the manifold of intuition": Below a certain (a priori indeterminable) degree of regularity and variety among the content of empirical intuitions, our understanding cannot make judgments; consequently we cannot under that condition be self-conscious. Consequently, this condition is a necessary, transcendental condition of possible experience. (Above this minimal level of regularity and variety, there is then a reflective issue about the extent to which our experience of the world can be systematized) The question now is: What, exactly, is the status of the principle of affinity in Kant's transcendental analysis, and is his analysis of that status adequate?

Kant explains the "hecessity" of transcendental conditions of possible experience exclusively in terms of the nature and functioning of our cognitive apparatus ineluctably structuring our experience in accord with those conditions. ${ }^{27}$ This thesis defines Kant's transcendental idealism. Kant argues that this kind of explanation also holds true of the transcendental affinity of the manifold of intuition. The following passage is Kant's most explicit statement of his argument:

I therefore ask, how do you make comprehensible to yourselves the thoroughgoing affinity of appearances, whereby they stand under constant laws, and must belong under such laws? 
On my principles it is easily comprehensible. All possible appearances, as representations, belong to the totality of a possible self-consciousness. But as self-consciousness is a transcendental representation, numerical identity is inseparable from it, and is a priori certain, because nothing can come to cognition except through this original apperception. Now, since this identity must necessarily enter into the synthesis of all the manifold of appearances, so far as this synthesis is to become empirical knowledge, the appearances are subject to a priori conditions, with which the synthesis of their apprehension must be in complete accord. Now the representation of a universal condition according to which a certain manifold can be uniformly posited is called a rule, and, when it must be so posited, a law. Thus all appearances stand in thoroughgoing connection according to necessary laws, and therefore in a transcendental affinity, of which the empirical is a mere consequence. ${ }^{28}$

In this passage Kant formulates the principle of the affinity of appearances as a principle which, prima facie, is open to alternative explanations, he challenges non-Kantians to explain it, and he claims that it is easy to explain on his own transcendental idealist principles. However, Kant is quite wrong about this; transcendental idealism cannot explain the occurrence of transcendental affinity at all.

I believe that Kant is quite correct, for reasons discussed above, that transcendental affinity of the manifold of intuition is a transcendental condition of the possibility of experience. However, Kant cannot explain why this principle is satisfied, or what is responsible for fulfilling this condition. The problem, simply put, is that Kant's idealist explanations of the transcendental affinity of the manifold of intuition conflate the ratio cognoscendi of this principle (which lies in Kant's transcendental analysis of the conditions of possible experience) with its ratio essendi (which his idealism cannot explain at all).

Kant's first contention on this head is that the "empirical affinity" of a manifold of intuition (or a set of appearances) is the mere consequence of its "transcendental affinity." 29 This cannot be correct. That an empirical manifold have affinity - in order for us to be selfconsciously aware of it - is indeed entailed by the requirements for unitary self-consciousness, but this entailment expresses a conditional necessity: If unitary self-conscious (human) experience occurs, then that subject is presented a manifold of associable appearances. However, the associability of that manifold of appearances is an independent fact, a sine qua non, of self-conscious experience; empirical affinity is an independent given, needed to satisfy the transcendental principle of affinity.

Kant's related claim, second, that the affinity of appearances is a necessary consequence (notwendige Folge) of the (transcendental) synthesis of imagination, ${ }^{30}$ is equivocal. Like the English "consequence," the German "Folge" can denote either logical or causal consequence. The affinity of a manifold is a logical consequence of the occurrence of 
the transcendental synthesis of imagination requisite for unitary apperception. Neither synthesis nor apperception could occur if the manifold of intuition lacked affinity. However, this affinity cannot be a functional product (causal consequence) of that synthesis, unless Kant were to give up his carefully qualified transcendental idealism and adopt full-blown subjective idealism. Our judgmental synthesis could only produce affinity of the manifold if it produced a substantial set of related empirical intuitions. This, however, would transgress the cardinal tenet of Transcendental Idealism that the matter of sensation is given to us. ${ }^{31}$ Unified selfconscious experience is the ratio cognoscendi of the occurrence of transcendental affinity of the manifold of intuition; but the occurrence of such transcendental affinity is the ratio essendi of unified self-conscious experience. In fact, transcendental idealism cannot explain the occurrence of transcendental affinity at all. ${ }^{32}$

Third, transcendental idealism is not at all the only possible explanation of affinity. ${ }^{33}$ The satisfaction of the principle of affinity is a distinct factor from its transcendental status as a necessary condition of unified self-conscious experience. This is because the "hecessity" that this principle be satisfied is conditional. Once this is recognized, then it is possible to recognize that the satisfaction of the principle of affinity is a function of the de facto orderliness of nature - a tenet espoused by naturalism and (common sense) realism.

Finally, it also cannot be the case that we are solely responsible for introducing order and regularity into the appearances we call nature, as Kant also claims. ${ }^{34}$ The basic reason is the same in each case: If the matter of sensation is given us a posteriori, then ex hypothesi we cannot generate its content. Consequently, we also can neither generate nor otherwise insure the regularities, the recognizable similarities and differences, within that content or among that set of given intuitions. The satisfaction of the principle of transcendental of affinity by any manifold of intuitions or appearances cannot be generated, injected, or imposed by that subject; in Kant's terms, it cannot be a 'transcendentally ideal" condition of possible experience. The satisfaction of the principle of affinity can be required by the cognitive nature of a subject, and thus it can be a transcendental condition for the possibility of that subject's unified self-conscious experience. This is a conditional necessity. The satisfaction of the transcendental principle of affinity is a contingent function of the specific characteristics of the a posteriori matter of sensation, namely the (recognizable) similarities among those characteristics of that matter. Kant was quite right to say that the principle of affinity concerns the content of experience, and that its ground lies in the object of experience. ${ }^{35}$ Consequently, the principle of affinity is certainly no more explicable on Kant's transcendental idealist account than on any naturalist account of the objects of knowledge. ${ }^{36}$ The result is that the transcendental affinity of the manifold of intuition is in fact a transcendental, formal and material condition of the possibility of experience. 


\section{the Manifold of Intuition}

The implications of transcendental affinity of the manifold of intuition for a naturalistically based transcendental analysis of the conditions of possible experience help elucidate several of Hegel's philosophical concerns and aims.

First, this provides some insight into Hegel's concern to combat Kantian skepticism.

Hegel was clearly aware that faith assumed priority over philosophy by appealing to skepticism, a strategy he observed in Jacobi, Kant, and Fichte. ${ }^{37}$ In Fichte and in Kant the skepticism which makes faith necessary results, Hegel contends, from the utter heterogeneity between our intellectual categories and the manifold of empirical intuition. ${ }^{38}$

Second, this may provide a rationale for, and perhaps some insight into, Hegel's dismissal of Kant's arguments in the Transcendental Aesthetic for idealism. Hegel accepted the standard objection to Kant's argument, known as the problem of the neglected alternative $^{39}$ One way of formulating the alternative Kant neglects is to claim that we can know a priori that the objects we experience must be in space and time because our forms of receptivity are spatial and temporal in the sense that they are only receptive to stimulation (affection) by spatial and temporal objects. ${ }^{40}$ In one form or another, this objection was commonplace in Hegel's day. Vaihinger cites the following among Hegel's predecessors who insisted, with greater or lesser acuity, on the problem of the neglected alternative: Lambert, Pistorius, Lotze, Fries, Maass, the anonymous author of 'Ueber Raum und Zeit," Flatt, Tiedemann, Schwab, G E Schulze (Aenesidemus), Selle, Ouvrier, Brastberger, Platner, J G Schultz, Maimon, Bardili, Schleiermacher, and Beneke. ${ }^{41}$

The interesting thing to note in the present connection is that this objection stems directly from principles internal to Kant's first Critique. Namely, the principle of the transcendental affinity of the manifold of intuition shows that $a$ priori transcendental arguments can show that an objectively real feature of objects - a feature not contributed by our cognitive functioning - can nevertheless necessarily be required for our cognitive functioning. That is the insight exploited by the "neglected alternative."

The prospect that mind-independent features of the world may nevertheless be necessary conditions knowable a priori for the possibility of experience opens the prospect of offering quasi-transcendental, regressive arguments to the conditions of the possibility of experience in conjunction with, indeed on the basis of, a realist or naturalist ontology. This is precisely what Hegel does in the Phenomenology. Moreover, Hegel clearly is aware of this prospect, as is shown by his extensive quotation from and enthusiasm for Kant's 'Refutation of Idealism" in Faith and Knowledge, in which he credits Kant with a "genuinely rational construction." 42 This same high estimation of Kant's Transcendental Deduction, together with dismissal of Kant's transcendental idealist account of space and time, is also found in the very important remark in the Logic, "On the Concept in General." ${ }^{43}$ The arguments which result from this recasting are "quasi-transcendental" because they do not support the very strong 
modal claims Kant made. For example, the principle that physical causality is external receives very strong pragmatic justification, but cannot be made out as "appodeictically necessary." (This is the upshot of Hegel's criticism of Kant's Metaphysical Foundations of Natural Science mentioned earlier.)

Finally, the implications of the transcendental affinity of the manifold of intuition and its objective, mind-independent ratio essendi provides some insight into Hegel's dual-aspect notion of the "Intellect" (Verstand), on the one hand as the structure of nature, and once again as the structure cognized by human subjects. The principle of the transcendental affinity of the manifold of intuition entails that there must be an order of nature which is regular and varied enough for us to come to cognize it and have experience at all. If this is true, then there is some sense in saying that there is a common structure which is instantiated in the world, recapitulated in our experience, and reconstructed in our thought and knowledge. This structure with its two-fold instantiation - in the world and in our knowledge of the world Hegel calls (in Faith and Knowledge) 'intellect" (Verstand). After all that has been shown here, it should be no surprise that he finds the roots of this view already in Kant's Transcendental Deduction:

If the intellect is to be considered for itself as abstraction of the form in its triplicity, it is all one whether it be regarded as intellect of consciousness or as intellect of nature, as the form of conscious or of non-conscious intelligence: just as in the ego the intellect is thought of as conceptualized, so in nature it is thought of as realized Suppose the intellect existed altogether in itself, then it would have as much reality in nature, ie, in a world outside of intellectual cognition, yet intelligible in and for itself, as it would have in an intellect thinking of itself in the form of intellectuality outside of nature. It would be experience taken subjectively as the conscious system, and experience taken objectively as the non-conscious system of the manifoldness and coherence of the world. ${ }^{44}$

As Henry Harris noted, Hegel's reference to "triplicity" ties his discussion to Kant's "Analytic of Concepts," which forms the point of departure of Kant's Transcendental Deduction. Specifically, it refers to Kant's remark, added to the second edition, about the integrity and systematicity of the Table of Categories. ${ }^{45}$ That Table, of course, gives Kant's account of the categorial structure of thought - and thus of the empirical world. Hegel here invites us to consider the structure of "intellect" (Verstand) 'for itself" or independently of Kant's view that this is the structure specifically of human understanding. On the basis of this abstraction, Hegel's reflections in this passage, especially his conclusion, plainly point toward a very nonKantian ontology. This ontology is a coherent, manifold structure which is instantiated as a "non-conscious system" in the world, where this system can become an object of 
consciousness in our experience of the world. This is one main element of the kind of ontological holism Hegel works out in his mature writings, which was designed to set "reason itself in harmony with nature." ${ }^{46}$ Hegel may not have known to call the transcendental principle which leads to such an ontology the "transcendental affinity of the manifold of intuition," but he clearly recognized that such a principle, and the realist ontology it requires, are entailed by Kant's transcendental analysis of the conditions of possible experience in his Transcendental Deduction and Refutation of Idealism. In this regard, Hegel was the first to recognize that Kant's transcendental arguments in the Transcendental Analytic can be made to stand independently of Kant's idealism, and can be put to the service of realism. ${ }^{47}$

Kenneth R Westphal

University of New Hampshire

1 For a brief statement of Hegel's principles of justification, which rest entirely on internal criticism, see my entry "Dialectic (Hegel)," in: E Sosa \& J Dancy, eds, A Companion to Epistemology (Oxford: Blackwell, 1992), 98-99. A fuller discussion is contained in "Hegel's Solution to the Dilemma of the Criterion," The History of Philosophy Quarterly 5 No 2 (1988), 173-88; rpt in: J Stewart, ed, The Phenomenology of Spirit Reader: A Collection of Critical and Interpretive Essays (Albany: SUNY, 1996). I explore and defend Hegel's views in full detail in Hegel's Epistemological Realism: A Study of the Aim and Method of Hegel's Phenomenology of Spirit (Dordrecht and Boston: Kluwer, 1989); hereafter abbreviated "HER".

2 "Glauben und Wissen. Oder die Reflexionsphilosophie der Subjektivität, in der Vollständigkeit ihrer Formen, als Kantische, Jacobische, und Fichtische Philosophie" (in: O Pöggeler, ed, Hegel: Gesammelte Werke, Hamburg: Meiner, 1968; abbreviated " $G W$ " GW IV 315-414; H S Harris \& W Cerf, trans, Faith and Knowledge; Albany: SUNY Press, 1977; hereafter abbreviated “ $G \& W$ ), $G \& W, G W$ IV 337.26-32/84 (my tr). Line numbers of $G W$ are indicated by decimals. Page references are given first to Hegel's German and then to the translation. The "negative solution" to which Hegel here refers is Kant's claim that the Antinomy is not necessarily a contradiction, if transcendental idealism is true.

$3 \quad G \& W, G W$ IV 396.11-18/165; my translation.

4 'Hegel's Critique of Kant's Moral World View," Philosophical Topics 19 No 2 (1991), 133-76. I should like to note that the two tenets Hegel ascribes to the moral world view" which I could not find again in Kant (ibid, note 2) Hegel explicitly ascribes to Fichte in the Differenzschrift. See 'Differenz des Fichte'schen und Schlling'schen Systems der Philosophie", GW IV, 59-60; H S Harris \& W Cerf, trans "The Difference Between Fichte's and Schelling's System of Philosophy," Albany: SUNY, 1977, 150-51; abbreviated hereafter as " $D$ ". A sixth objection Hegel makes concerning Kant's view of God as an ens realisimum is discussed by Allen Wood and decided in Kant's favor in Kant's Moral Religion (Ithaca: Cornell University Press, 1970), 135-145. On Hegel's objections to this doctrine in his Dissertation, see Hans Friedrich Fulda, "Hegels Dialektik und die transzendentale Dialektik Kants," Giornale di Metafisica, Nuova Serie 9, 1987, 265-94, esp 282-85. Regarding the issues Fulda raises also see Michael Wolff, Der Begriff des Widerspruchs. Eine Studie zur Dialektik Kants und Hegels (Königstein/Ts: Hain, 1981), 129-41. In §IX of 'Hegel's Critique of Kant's Moral World View" I show that some important elements of 
Hegel's critique of Kant applies to Onora O'Neil's Constructions of Reason (Cambridge: Cambridge University Press, 1989). In 'How 'Full' is Kant's Categorical Imperative?" (Jahrbuch für Recht und Ethik/Anmual Review of Law and Ethics 3, 1995, 465-509) I make a similar case regarding Barbara Herman, The Practice of Moral Judgment (Cambridge: Harvard University Press, 1993).

6 I have worked out these problems on grounds strictly internal to Kant's philosophy in the following essays: 'Does Kant's Metaphysical Foundations of Natural Science Fill a Gap in the Critique of Pure Reason?" (Synthese 103 No 1, 1995, 43-86.); 'Kant's Dynamic Constructions" (Journal of Philosophical Research 20, 1995, 381-429); and 'Kant's Proof of the Law of Inertia" (in: H Robinson, ed, Proceedings of the 8th International Kant Congress; Milwaukee: Marquette University Press, 1995; II.1, 413-24). I have set out the basis for ascribing this objection to Hegel in "On Hegel's Early Critique of Kant's Metaphysical Foundations of Natural Science," in: S Houlgate, ed, Hegel and the Philosophy of Nature (Albany: SUNY, 1996). I should like to note that my essay on Kant's treatment of the law of inertia is not quite adequate. First, Kant's statement of Newton's law includes the term "speed" ("Geschwindigkeit"), which Kant likely understood in Newtonian, proto-vectorial terms. If so, his statement of Newton's law is correct. However, that would make Kant's statement redundant, since he states beforehand sameness of direction ("Richtung'). Translating Kant's term "Geschwindigkeit" by "velocity," as I followed Ellington in doing, may read too much Newton into Kant's actual formulation. Most importantly, though, my main objection does hold, that Newton's law does not follow from Kant's second law of mechanics. Second, insofar as my examples show that the errant billiard balls I describe are alive, where life, according to Kant, "is the capacity of a substance to determine itself to change" (MAdN IV 544.7-10), my examples show that billiard balls could be alive even though they consist solely of external spatial relations and utterly lack any psychic states. This highlights the crucial way in which Kant's key premise, that "we know of no other internal principle of a substance to change its state but desire ..., etc. (MAdN IV 544.10-14), concerns empirical ignorance. Moreover, my examples of non-Newtonian collisions do not require that billiard balls be alive, only that they respond to collisions in ways that violate Newton's Second Law, say, by spiraling away. In this regard, my examples underscore the crucial way in which Newton's law is based on an empirical, physical postulate concerning inertia and the rectilinear nature of inertial motion, rather than on any metaphysical principle of the sort Kant seeks to justify. In these regards, my objections may require more careful and thorough presentation, but I submit that they are basically sound. I thank William Harper and Steven Palmquist for raising these points with me.

7 Hegel clearly cites the B edition in $G \& W, G W$ IV $328.22 / 71,364-66 / 120-24$; and in the first edition Logik (1816) GW XII 18.9, 26.5.

8 "Affinity, Idealism, and Naturalism: The Stability of Cinnabar and the Possibility of Experience," Kant-Studien (forthcoming). The sketch I give below of Kant's views draws from my much more extensive treatment in this essay.

9 See Frederick C Beiser, The Fate of Reason; Cambridge, Ma: Harvard University Press, 1987.

10 Hegel's Development: Night Thoughts (Jena 1801-1806); Oxford: Clarendon, 1984.

$11 H E R$. For a précis see my entry, 'Hegel', in A Companion to Epistemology, op cit, 167-170. 
14 "... the absolute judgment of idealism as expounded by Kant may, and on this level, must be grasped in such a way that the manifold of sensibility, empirical consciousness as intuition and sensation, is in itself something unintegrated, that the world is in itself falling to pieces, and only gets objective coherence and support, substantiality, multiplicity, even actuality and possibility, through the good offices of human selfconsciousness and intellect" ( $G \& W, G W$ IV 330.21-27/74-75; quoted more extensively below, note 20 ).

15 'Because of the absolute subjectivity of reason and its being set against reality, the world is, then, absolutely opposed to reason. Hence it is an absolute finitude devoid of reason, a sense-world lacking organization [unorganische Sinnemwelt]" (G\&W, GW IV 406.9-11/179; contra Fichte).

$16 \quad G \& W, G W$ IV 333.24-26/78.

$17 G \& W, G W$ IV 341.11-13/89; $C f K d U \S 76$, V 401.34-35, $K d r V$ A50=B74, A51$52=\mathrm{B} 75-76, \mathrm{~A} 65=\mathrm{B} 89-90$, III 74.9-18, 75.5-26, 83.18-19. I refer to the volume, page, and line numbers of: "Kants Gesammelte Schriften," Königlich Preußische [now Deutsche] Akademie der Wissenschaften, Berlin: G. Reimer [now De Gruyter], 1902-; ususally referred to as "Akademie-Ausgabe."

18 For Kant "The phenomena must be given, and they are filtered by the categories. Now this filtering may produce all sorts of correct concepts, to be sure, but it does not confer any necessity on the phenomena; and the chain of necessity is the formal aspect of what is scientific in the construction. The concepts remain contingent with respect to nature just as nature does with respect to the concepts. For this reason correctly constructed syntheses by way of the categories would not necessarily have to be corroborated by nature itself. Nature can only offer variegated displays that could count as contingent schemata for laws of the understanding, exemplary by-plays whose living peculiarity would fade away precisely because only the determinations of reflection are recognized in them. And conversely the categories are only impoverished schemata of nature" ( $D, G W$ IV 70.4-13/164).

19 "One might be tempted by this semblance of identity into regarding this thinking as reason. But because this thinking has its antithesis (a) in an application of thinking and (b) in absolute materiality (Stoffheit), it is clear that this is not the absolute identity, the identity of subject and object which suspends them both in their opposition and grasps them within itself, but a pure identity, that is and identity originating through abstraction and conditioned by opposition, the abstract intellectual concept of unity, one of a pair of fixed opposites" $(D, G W$ IV 18.34-19.2/97; contra Reinhold; $c f D, G W$ IV 82.20-33/180-81).

'What is opposite to thought is, through its connection with thought, determined as something thought $=\mathrm{A}$. But such a thought, such a positing $=\mathrm{A}$ is conditioned by an abstraction and is hence something opposite. Hence, that which is thought, besides the fact that it has been thought of $=\mathrm{A}$, has still other determinations $=\mathrm{B}$, entirely independent of being merely determined [as something thought] by pure thought. These other determinations are brute data for thought. Hence for thought as the principle of the analytic way of philosophizing, there must be an absolute stuff. We shall discuss this further below. With this absolute opposition as foundation the formal program, in which the famous discovery that philosophy must be reduced to logic [Reinhold, Beiträge I, 98] consists, is allowed no immanent synthesis save that provided by the identity of the intellect, i.e., the repetition of A ad infinitum. But even for this repetition the identity needs some $B, C$, etc. in which the repeated $A$ can be posited In order for $A$ to be repeatable, B, C, D, etc. are a manifold, in which each is 
opposed to the other. Each of them has particular determinations not posited by $\mathbf{A}$. That is to say, there exists an absolute manifold stuff. Its B, C, D, etc. must fit in [Bardili] with A, as best it can" ( $D, G W$ IV 26.34-27.12/108-09).

"For even the slight synthesis called application involves a transition of the unity into a manifold, a union of thinking and matter, and hence includes what is called the inconceivable. To be capable of synthesis, thinking and matter must not be absolutely opposed to each other; they must be posited as originally one, and so we would be back with that tiresome identity of subject and object in transcendental intuition ..." $(D$, GW IV 88.14-19/188; contra Reinhold or Bardili).

'In addition to the postulated matter and its deduced manifoldness, [Bardili's] Outline [of Logic] also postulates an inner capacity and suitability of matter to be thought. Besides the materiality that is to be annulled in thinking, there must be something that cannot be annulled by thinking; and even the perceptions of a horse do not lack it. It is a form that is independent of thinking, and since by the law of nature form cannot be destroyed by form, the form of thinking has to fit itself into it. In other words, besides the materiality that cannot be thought, besides the thing in itself, there must be an absolute stuff which can be represented and is independent of the representing subject, thought in representation it is connects with the form" ( $D, G W$ IV 88.23-31/188).

"Imagination, however, which is reason immersed in difference, is at this level raised only to the form of infinitude and fixated as intellect. This merely relative identity necessarily opposes itself to, and is radically affected by, the particular as something alien to it and empirical. The in-itself of both, the identity of this intellect and the empirical, ie, the a priori aspect of judgment, does not come to the fore; philosophy does not go on from judgment to a priori inference [A298-309=B355-66], from the acknowledgement that the judgment is the appearing of the in-itself to the cognition of the in-itself. It is for this reason that the absolute judgment of idealism as expounded by Kant may, and on this level, must be grasped in such a way that the manifold of sensibility, empirical consciousness as intuition and sensation, is in itself something unintegrated, that the world is in itself falling to pieces, and only gets objective coherence and support, substantiality, multiplicity, even actuality and possibility, through the good offices of human self-consciousness and intellect. All this is an objective determinateness that is man's own perspective and projection. Thus the whole deduction gets the easily grasped meaning that things in themselves and the sensations are without objective determinateness - and with respect to the sensations and their empirical reality nothing remains but to think that sensation comes from the things in themselves. For the incomprehensible determinateness of the empirical consciousness comes altogether from the things in themselves, and they can be neither intuited nor yet cognized In experience, the form of intuition belongs to the figurative synthesis, the concept to the intellectual synthesis [B151]. No other organ remains for the things in themselves but sensation; for sensation alone is not a priori, or in other words, it is not grounded in man's cognitive faculty for which only appearances exist. The objective determinateness of sensations is their unity, and this unity is merely the self-consciousness of an experiencing subject. So it is no more something truly $a$ priori and existing in itself than any other subjectivity" (G\&W, GW IV 330.8-331.4/7475).

'Identity of this formal kind finds itself immediately confronted by or next to an infinite non-identity, with which it must coalesce in some incomprehensible way. On one side there is the ego, with its productive imagination or rather with its synthetic unity which, taken thus in isolation, is formal unity of the manifold. But next to it there is an infinity of sensations and, if you like, of things in themselves. Once it is abandoned by 
the categories, this realm cannot be anything but a formless lump, even though, according to the Critique of Judgment, it is a realm of beauteous nature and contains determinations with respect to which judgment cannot be subsumptive but only reflecting. Objectivity and stability derive solely from the categories; the realm of things in themselves is without categories; yet it is something for itself and for reflection" ( $G \& W, G W$ IV 332.16-27/76-77).

'In this way, then, the objectivity of the categories in experience and the necessity of these relations become once more something contingent and subjective. This intellect is human intellect, part of the cognitive faculty, the intellect of a fixed ego-point. The things, as they are cognized by the intellect, are only appearances. They are nothing in themselves, which is a perfectly truthful result. The obvious conclusion, however, is that an intellect which has cognizance only of appearances and of nothing in itself, is itself only appearance and is nothing in itself' ( $G \& W, G W$ IV 332.34-333.2/77).

$C f$ “... this form [Fichte's formal idealism] does not alter the common and incomprehensible necessity of empirical existence in the slightest. Whether reality appears to us as the qualities of things or as our sensation, we cannot think for a moment that we have here a genuine ideality of actuality and of the real side [of experience]" ( $G \& W, G W$ IV 389.17-20/156).

'What this formalism [in Jacobi and Fichte] comes down to basically is that either the pure concept, the empty thought, supervenes incomprehensibly upon a content, a determination of the concept, or vice versa: the determination supervenes incomprehensibly upon the indeterminateness [of the pure concept]" ( $G \& W, G W$ IV 389.26-28/156).

$21 D, G W$ IV $6.11-15 / 80-81 . C f$ 'In Kant, too, nature is posited as absolutely determined But it cannot be thought of as determined by what Kant calls understanding, for the variety of particular phenomena are left undetermined by our human discursive understanding; so they must be thought of as determined by another understanding. However, this determination by another understanding is to be taken merely as a maxim of our reflecting judgment. Nothing is asserted about the actual existence of this other understanding" ( $D, G W$ IV 53-28-34/143-44).

"This is, finally, the place to exhibit the most interesting point in the Kantian system, the point at which a region is recognized that is a middle between the empirical manifold and the absolute abstract unity [KdU Preface, §III]" (G\&W, GW IV 338.3537/85).

22 Cf Henry Allison, Kant's Transcendental Idealism (New Haven: Yale University Press, 1983), 250.

23 H J Paton recognizes that the matter of sensation must result from the sensory affection due to things in themselves (Kant's Metaphysic of Experience; London: George Allen \& Unwin, 1936; I 139-40). I have argued that he is quite right about this in "Noumenal Causality Reconsidered" (forthcoming). Hegel recognized that this must be Kant's view ( $G \& W, G W$ IV 330.34-37/74-75; quoted above, note 20 ).

$24 K d r V$ A112-13, IV 85.3-10; A653-54=B681-82, III 433.14-29.

$25 K d r V$ A121-123, IV 90.6-91.2; some emphases added; tr Kemp Smith, Immamuel Kant's Critique of Pure Reason (New York: St. Martins, 1929), 144-145; translation emended

$26 K d r V$ A653-54=B681-82; III 433.14-29; emphasis added; tr Kemp Smith, 539-540; translation emended

27 Kant states this most directly in the Prolegomena: 'Even the main principle expounded throughout this section, that the universal laws of nature can be known $a$ priori, leads of itself to the proposition that the highest prescription of laws of nature 
must lie in ourselves, that is, in our understanding; and that we must not seek the universal laws of nature in nature by means of experience, but conversely must seek nature, regarding its universal conformity to law, merely in the conditions of the possibility of experience which lie in our sensibility and understanding. For how were it otherwise possible to know these laws a priori, since they are not rules of analytic knowledge but are true synthetic extensions of it? Such a necessary correspondence of the principles of possible experience with the laws of the possibility of nature can only proceed from two causes: either these laws are drawn from nature by means of experience, or conversely, nature is derived from the laws of the possibility of experience in general and is utterly one with the latter's strict universal lawfulness. The first [cause] contradicts itself, for the universal laws of nature can and must be known a priori (that is, independently of all experience) and can and must be the foundation of all empirical use of the understanding; therefore only the second [cause] remains" (Prol \$36, IV 319.11-30; translated by L W Beck, Kant Selections [New York: Macmillan, 1988], 199-200; translation emended). Cf B41, A23=B37-38, A2628=B42-44, A195-96=B240-41, III 54.21-27, 52.8-14, 55.1-56.19, 171.25-172.9; A101-02, A113-14, A121-123, A125-26, IV 78.20-33, 85.10-28, 90.6-91.2, 92.14-24. $K d r V$ A113-14, IV 85.10-28; tr Kemp Smith, op cit, 139-140; translation emended Kant makes essentially the same argument again at A101-02, A122, A123, A125-26; IV 78.20-33, 90.26-30, 90.37-91.2, 92.14-24. $K d r V$ A 114, quoted above, p 9.

$30 \quad K d r V$ A123, IV 90.37-91.2.

31 Cf Paton: ' 1 believe that the empirical differences in the shapes and sizes of objects, like their empirical qualitative differences, must be ascribed to the 'influence' of thingsin-themselves. ... Only what is strictly universal is imposed by the mind upon objects. Empirical differences are particular determinations of the universal, but their particularity is not due to the mind and must be due to things. If this view be given up, I do not see how the Critical Philosophy can be made intelligible" (op cit, I 139-40). Affinity consists in regularities among the particularities of the contents of sensations. Contra KdrV A101-02, A113-14, and A122; IV 78.20-33, 85. 10-28, 90.26-30. Contra KdrV A101-02, A113-14, and A122; IV 78.20-33, 85.10-28, 90.26-30. KdrV A125-26, IV 92.14-24. $K d r V$ A1 12-13, IV 85.3-10; A653-54=B681-82, III 433.14-29. Contra KdrV A113-14, IV 85.10-28; quoted above, p 9.

$C f$ 'Reason, having in this way become mere intellect (Verstand), acknowledges its own nothingness by placing that which is better than it in a faith outside and above itself, as a beyond. This is what has happened in the philosophies of Kant, Jacobi, and Fichte. Philosophy has made itself the handmaid of faith once more" (G\&W, GW IV 315.28-316.1/56). On the epistemological significance of Hegel's opposition to this kind of faith, see my 'Harris, Hegel, and the Truth about Truth", in: G Browning, ed, The Phenomenology of Spirit: A Reappraisal (Dordrecht: Kluwer, 1996).

38 "The immediate product of this formal idealism as we have seen it arise [in Fichte], has, then, the following shape. A realm of experience without unity, a purely contingent manifold, on one side, is confronted by an empty active thought on the other. If the empty thought is posited as a real, active force, then like everything else that is objective, it must be recognized as something ideal. Or, in order to put the antithesis of the thought and the manifold realm of empirical necessity in its pure form, the thought must not be posited as a real active force - ie, in the context of reality but purely for itself, as empty unity, as universality completely set apart from particularity. Kant's pure reason is this same empty thought, and reality is similarly 
opposed to that empty identity, and it is precisely the lack of concordance between them that makes faith in the beyond necessary" ( $G \& W, G W$ IV 395.23-33/164).

Cf Vorlesungen über die Geschichte der Philosophie III (Werke in Zwanzig Bänden; Moldenhauer \& Michel, eds; Frankfurt/M: Suhrkamp, 1970) XX 341; Enz $\$ \$ 254$ Anm (1817: §197), 448 Zusatz.

40 I argue that Allison's "defense" of Kant's arguments for idealism fails to meet this objection in $H E R$, ch 3 . There I developed this objection independently; here I show that Hegel had the grounds to develop it internally to Kant's principles.

Vaihinger, Commentar zu Kants Kritik der reinen Vernunft (Stuttgart, Berlin, Leipzig: Union Deutsche Verlagsgesellschaft, 1892), II 142 note 2, 143, 144 note 1, 307, 312ff., esp 323. He concludes that the objection is sound (ibid, 148, 289-90, 310). $G \& W, G W$ IV 365.18-367.27/123-25.

43 Wissenschaft der Logik (GW XII; hereafter “WL') II 17-18/Miller, tr, Hegel's Science of Logic (New York: Humanities, 1969; hereafter " $S L$ '), 584; $C f H E R$, ch 11, esp §III.

$44 \quad G \& W, G W$ IV $334.18-27 / 79 ;$; $341.2-8 / 89, W L$ (GW XII) II $20.11-18 / S L$ 586. I discuss these latter passages in "Hegel, Idealism, and Robert Pippin" (International Philosophical Qwarterly 33 No 3, 1993, 263-72), 268-69.

$45 \$ 11, \mathrm{~B} 109-113$; III 95-97. This passage is new in the second edition, thus again suggesting which edition Hegel used Regarding Hegel's early attention to Kant's Table of Judgments, see my 'Kant, Hegel, and the Fate of 'the' Intuitive Intellect," in:

S Sedgewick, ed, The Idea of a System of Transcendental Idealism (Cambridge: Cambridge University Press, forthcoming).

$46 D, G W$ IV 8.8-10/3. I sketch Hegel's ontology in $H E R$, ch 10 . In response to my criticisms ("Hegel, Idealism, and Robert Pippin,"op cit) of his book (Hegel's Idealism; Cambridge: Cambridge University Press, 1989), Robert Pippin made the counterobjection to my interpretation of Hegel's ontology that I attributed to Hegel an idealism like that of the British idealists, an attribution Rolf-Peter Horstmann had conclusively refuted (Ontologie und Relationen: Hegel, Bradley, Russell und die Kontroverse über interne und externe Beziehungen; Königstein/Ts: Athenäum/Hain, 1984). (Pippin's charge is made in 'Hegel's Original Insight," International Philosophical Quarterly 33 No 3, 1993, 285-295; 290.) Pippin is quite mistaken in contending that I ascribed such an ontology to Hegel. Although Horstmann and I emphasized different aspects of Hegel's ontology, we are quite agreed that Hegel's ontology is not at all of the kind found in the British Idealists, although it does share a very few broad similarities with it (Horstmann, 248), and we agree that it is not touched by Russell's objections to British idealism. Horstmann summarizes one central line of Russell's argument as follows: 'If Monism and Monadism are untenable, then the only alternative is some kind of pluralism. And if Monism and Monadism cannot be established without the assumption of internal (irreal, mental) relations, then it follows, that the assumption of non-internal (external) relations implies a non-monistic, non-monadistic (pluralistic) position" (Horstmann, 195; my tr). As Horstmann notes, it is simple to develop a slightly more subtle ontology which would admit, for example, some but not exclusively "external" relations (ie, relations which are not essential to the relata). This would immediately escape Russell's objections ( $c f$ Horstmann, 193-94). Hegel held such a view, and his view reveals an important fallacy in Russell's argument. Russell's argument equivocates between two senses of "Internal". "Within the one monistic substance" vs "Essential to the relata." The controversy about "Internal" relations in Bradley's sense concerns this second sense of "Internal," which Hegel rejected as an exhaustive or exclusive class of 
relations. I ascribe to Hegel the view that some, indeed many relations are essential to objects, namely, their causal properties. These properties are modal in the sense that they constitute classes of possible particular causal relations. They are further questions, which of these possible causal relations are in fact realized as actual causal interactions during the history of any particular object, and which of these actual causal interactions are in fact essential to that object ( $C f$ Horstmann, 225). It is still another question which contingent circumstances a thing happens to occupy during its history. All three of these questions were left open in my sketch of Hegel's ontology. In no way did I ascribe to Hegel the view that every relation, or even every particular causal interaction, is essential to a thing and thus in this sense is "Internal" to it. Hegel certainly did not undertake, nor did I ascribe to him, the supposed "monistic reduction" of multi-place to single-place predicates which Russell criticized (Cf Horstmann, 21620, 228-31). Hegel also didn't conclude from its supposed "internality" that a relation is "unreal." These facts distinguish Hegel's ontology fundamentally from Bradley's, and also removes Hegel's ontology from the scope of Russell's objections ( $c f$ Horstmann, 103-05). Finally, for his whole career Hegel criticized the cognitively impassable cleft between appearance and reality which is basic to Bradley's philosophy, and at least from 1804 onward Hegel propounded a discursive theory of knowledge of the absolute, an absolute which consists in the systematic totality of all appearances. In all these regards, too, Hegel fundamentally opposed Bradley's philosophy. In sum, Pippin's objection to my interpretation of Hegel's ontology is entirely unfounded.

47 The use of Kant's arguments in the Transcendental Analytic, especially in the Analogies and the Refutation of Idealism, in service of realism is a common theme in Neo-Kantianism and in Analytic interpretation of Kant since Strawson. Most recently, Paul Guyer has argued that Kant's only successful transcendental arguments are to be found in the Analogies, and that these arguments support realism (Kant and the Claims of Knowledge; Cambridge: Cambridge University Press, 1987).

I gratefully acknowledge that preliminary work on this essay was begun during an annual research grant from the National Endowment for the Humanities (1992) and that I was enabled to write this essay by a research grant from the Alexander von Humboldt Foundation (Spring 1995). 